\title{
Mathematical Model and Its Solution of the Optimization Problem in Human Resource Management of Chinese State-Owned Enterprises and Institutions
}

\author{
Xuhong Song ${ }^{1}$, Jiajia $\mathrm{Liu}^{2}$, Hongshun $\mathrm{Li}^{2}$, Han Long ${ }^{3, *}$ \\ ${ }^{1}$ School of System Engineering of NUDT, Changsha, Hunan, P.R. China \\ ${ }^{2}$ Center for Teaching and Research Service of NUDT, Changsha, Hunan, P.R. China \\ ${ }^{3}$ College of Liberal Arts of NUDT, Changsha, Hunan, P.R. China. \\ *Corresponding author. Email: longhan2996@sina.com
}

\begin{abstract}
In order to solve the optimization problem of human resource allocation, the paper analyzes the relevant policies and rules of human resource cost, adopts the integer programming method to optimize the human resource allocation. The model built shows the flexibility of the optimized model. This study provides a good way to quantitatively analyze the optimal allocation of human resources in Chinese state-owned enterprises. Different enterprise laws can learn from the ideas and methods of this paper to solve the optimal allocation of human resources according to their own cost tolerance, corporate culture, policy characteristics and other considerations.
\end{abstract}

Keywords: State owned enterprises, human resources management, linear programming, Cost constraints

\section{INTRODUCTION}

In recent years, the research on quantitative planning of human resource planning has been paid more attention to and become a research hotspot [1]. Human resource allocation plays an important role in state-owned enterprises. State-owned enterprises are wholly state-owned enterprises, wholly state-owned companies and state-owned capital holding companies that perform the duties of investors on behalf of the State and local governments. They are controlled by the state over their personnel and capital. If a state-owned enterprise wants to develop, it is not only closely related to its technology, but also closely related to its personnel distribution and cost reduction. Cost saving is an important foundation for the stable development of enterprises. Therefore, we should reduce the cost consumption, strictly control the production and circulation of products, reduce the cost consumption, open the source and reduce the consumption, and avoid waste[2,3]. After enterprises take actions in cost reduction, the allocation of human resources management is also the key to the development of enterprises. The so-called human resource management includes systems, decrees, procedures and methods for the effective development, rational allocation, full utilization and scientific management of human resources [4]. The paper mainly rationally allocates human resources through linear programming and integer programming to manage the recruitment, training, assessment, incentive system of state-owned enterprise employees, and reduces the cost of the enterprise so that the enterprise can develop in a balanced way.
Integer programming has been applied in human resource planning. For example, with consideration of avoiding collisions and obstacles, linear and integer programming is used to plan the optimal path with the least fuel consumption of multiple vehicles[5]; By representing the operating conditions as integer variables and the monitoring problem as an integer quadratic programming problem, the load of a new type of non-intrusive device can be monitored through integer programming[6]; In multi-class active learning, using integer programming can more effectively solve the problem of active learning with limited label resources and many categories[7].

In this paper, according to the characteristics of human resource recruitment and distribution planning in China's state-owned enterprises, we will carry out the research on human resource planning under the control of cost objectives. This paper will fully explore the unique corporate culture of China's state-owned enterprises, hoping to take the historical factors of Chinese culture as constraints, fully explore and integrate them into the mathematical model of planning problems.

\section{ANALYSIS ON THE CHARACTERISTICS OF HUMAN RESOURCES ALLOCATION IN CHINESE STATE-OWNED ENTERPRISES}

The distribution of human resources in China's state-owned enterprises has the characteristics of administration. Due to the implementation of the hierarchical management mode from top to bottom, the establishment of departments, offices and other departments with obvious administrative 
color, the minister and the director are essentially officials. Therefore, there is a potential official culture of "superior and subordinate" workplace politics and learning to be good officials, leading to the pursuit of affairs by some excellent technical employees. In a sense, human resources in Chinese state-owned enterprises will show the characteristics of "high-quality resources upward concentration". Of course, with the promotion of reform and opening up, such characteristics are no longer typical and prominent.

The distribution of human resources in state-owned enterprises in China has the characteristics of cross flow. Many technical officials will be transferred from one department to another as leaders. The two departments may have totally different businesses.

China's state-owned enterprises pay attention to the characteristics of qualifications in human resource allocation. The employees or leaders of the two departments may have totally different businesses, but as long as their qualifications are close, it means that they have similar abilities. One of the leaders can move to the position of the leader with similar qualifications. On the other hand, an employee may be competent for an important position, but if his qualifications do not meet the potential requirements, he will be difficult to get that position.
The following table is a sample table of the collection of human resources post responsibility data of a state-owned enterprise. From the structure of the table, we can see the obvious administrative characteristics and the importance of qualifications.

\subsection{Policy and Rule Modeling of Human Resource Allocation}

According to the project team members' investigation of human resources related policies of several state-owned enterprises in China, combined with the analysis of human resources business forms, the main influencing factors of human resources allocation of a state-owned enterprise in China are extracted, and representative departments are selected to establish an organizational structure model, so as to conduct a more quantitative study of human resources allocation model of state-owned enterprises in China. The organizational structure chart of a Chinese state-owned enterprise used for human resource cost analysis, the general organizational structure of Chinese state-owned enterprises will be very complex, but the basic structure is similar.

Table 1 Sample table of collection table of human resources post responsibility data

\begin{tabular}{|c|c|c|c|}
\hline Name of the post & \multicolumn{2}{|c|}{} \\
\hline department & & Belongs to shift & \\
\hline Job Category & & Incompatible positions & \\
\hline Job overview & \multicolumn{3}{|c|}{ Main relationship } \\
\hline \multicolumn{3}{|c|}{ Direct Subordinates } & \\
\hline immediate superior & & External cooperative relationship & \\
\hline Internal collaboration & & Job Responsibilities \\
\hline \multicolumn{2}{|c|}{} \\
\hline General management & key performance indicators
\end{tabular}

Table 2 Technical grade, average wage and quantity demand information of post personnel

\begin{tabular}{|c|c|c|c|}
\hline Number of field demand & Average personal salary & Personal technical level & Domain name \\
\hline \multirow{3}{*}{5} & 750000 & expert-level & \multirow{3}{*}{ domain A } \\
\hline & 520000 & quasi expert & \\
\hline & 330000 & common level & \\
\hline \multirow{3}{*}{10} & 600000 & expert-level & \multirow{3}{*}{ domain B } \\
\hline & 520000 & quasi expert & \\
\hline & 330000 & common level & \\
\hline \multirow{2}{*}{4} & 510000 & quasi expert & \multirow[t]{2}{*}{ domain $\mathrm{C}$} \\
\hline & 330000 & common level & \\
\hline 3 & 510000 & quasi expert & domain D \\
\hline \multirow{3}{*}{7} & 510000 & expert-level & \multirow{3}{*}{ domain $\mathrm{E}$} \\
\hline & 510000 & quasi expert & \\
\hline & 330000 & common level & \\
\hline \multirow{2}{*}{5} & 510000 & quasi expert & \multirow{2}{*}{ domain $\mathrm{F}$} \\
\hline & 330000 & common level & \\
\hline \multirow{2}{*}{4} & 450000 & expert-level & \multirow{2}{*}{ domain $\mathrm{G}$} \\
\hline & 510000 & quasi expert & \\
\hline \multirow{2}{*}{2} & 330000 & quasi expert & \multirow{2}{*}{ domain $\mathrm{H}$} \\
\hline & 270000 & common level & \\
\hline \multirow{2}{*}{7} & 3150000 & quasi expert & \multirow{2}{*}{ domain I } \\
\hline & 240000 & common level & \\
\hline 3 & 180000 & common level & domain $\mathrm{J}$ \\
\hline
\end{tabular}


Based on China's state-owned enterprises, information tables of constraint models such as policies, corporate culture and balanced demand for human resource optimization are formed:

According to the human resource testimonies, corporate culture and organizational structure characteristics of Chinese state-owned enterprises, this paper analyzes the case of human resource allocation planning of Chinese stateowned enterprises. Taking a high-tech state-owned enterprise as an example: according to the policies and documents of human resource management of the enterprise, we conclude the cost information needed to create the human resource planning model as follows:

According to the policy, there should be no more than 80 experts, 100 quasi experts, and 50 ordinary level personnel in all domains. The salary of expert level personnel in domain $\mathrm{A}$ is 750000 . The product of the salary and the number of expert is the total salary of expert level personnel in domain $\mathrm{A}$, which is same to other domains for the calculation of total salary The expert level personnel in all domains shall not exceed $10 \%$ of the total personnel in different fields, the quasi expert level personnel shall not be less than $50 \%$ of the total personnel, and the ordinary level personnel shall not exceed $40 \%$.

\subsection{Optimization Model of Human Resource Allocation in Chinese State-Owned Enterprises}

After the completion of data collection and validation, this paper proposes a human resource planning model based on linear programming method. Considering the actual problems and conditions of human resources, the operational variables that the planning depends on must be integer variables. Therefore, the human resource planning model based on linear programming method can be converted into integer planning problems. The planning model of this paper contains 21 decision variables and 17 restrictive conditions, which are as follow.

The planning objective function:

$$
\begin{aligned}
\operatorname{Min}(\mathrm{z})= & 750000 x_{1}+600000 x_{2}+450000 x_{4}+52000\left(x_{5}+x_{6}\right)+510000\left(x_{3}+x_{7}+x_{8}+\right. \\
& \left.x_{9}+x_{10}+x_{11}\right)+330000 x_{12}+315000 x_{13}+330000\left(x_{14}+x_{15}+x_{16}\right. \\
& \left.+x_{17}+x_{18}\right)+270000 x_{19}+240000 x_{20}+180000 x_{21}
\end{aligned}
$$

The constraints:

$$
\begin{aligned}
& \left\{\begin{array}{l}
x_{i} \in Z^{+}, x_{i} \geq 1, x_{3}+x_{9}+x_{17}=7, x_{13}+x_{20}=7, i=1, \cdots 21 \\
x_{12}+x_{19}=2, x_{11}+x_{4}=4, x_{21}=3, x_{1}+x_{2}+x_{3}+x_{4} \leq 70
\end{array}\right. \\
& x_{5}+x_{6}+x_{7}+x_{8}+x_{9}+x_{10}+x_{11}+x_{12}+x_{13} \leq 100 \\
& x_{1}+x_{2}+x_{3}+x_{4} \leq 0.1\left(x_{1}+x_{2}+x_{3}+x_{4}+x_{5}+x_{6}+x_{7}+x_{8}+x_{9}+x_{10}+x_{11}\right. \\
& \left.+x_{12}+x_{13}+x_{14}+x_{15}+x_{16}+x_{17}+x_{18}+x_{19}+x_{20}+x_{21}\right) \\
& \left.60000\left(x_{14}+x_{15}+x_{16}+x_{17}+x_{18}+x_{19}+x_{20}+x_{21}\right) \leq 3600000\right) \\
& 330000\left(x_{14}+x_{15}+x_{16}+x_{17}+x_{18}\right)+270000 x_{19}+240000 x_{20}+180000 x_{21} \leq 6195000 \\
& 520000\left(x_{5}+x_{6}\right)+510000\left(x_{7}+x_{8}+x_{9}+x_{10}+x_{11}\right)+330000 x_{12}+315000 x_{13} \leq 12270000 \\
& 750000 x_{1}+600000 x_{2}+510000 x_{3}+450000 x_{4} \leq 3150000 \\
& x_{14}+x_{15}+x_{16}+x_{17}+x_{18}+x_{19}+x_{20}+x_{21} \leq 50 \\
& 0.5\left(x_{1}+x_{2}+x_{3}+x_{4}+x_{5}+x_{6}+x_{7}+x_{8}+x_{9}+x_{10}+x_{11}+x_{12}+x_{13}+x_{14}+x_{15}+\right. \\
& \left.x_{16}+x_{17}+x_{18}+x_{19}+x_{20}+x_{21}\right) \leq x_{5}+x_{6}+x_{7}+x_{8}+x_{9}+x_{10}+x_{11}+x_{12}+x_{13}
\end{aligned}
$$




$$
\begin{aligned}
& 0.4\left(x_{1}+x_{2}+x_{3}+x_{4}+x_{5}+x_{6}+x_{7}+x_{8}+x_{9}+x_{10}+x_{11}+x_{12}+x_{13}+x_{14}+x_{15}\right. \\
& \left.+x_{16}+x_{17}+x_{18}+x_{19}+x_{20}+x_{21}\right) \leq x_{14}+x_{15}+x_{16}+x_{17}+x_{18}+x_{19}+x_{20}+x_{21}
\end{aligned}
$$

The above are the 10 constraint conditions established. Among them, constraints (2) to (4) indicate the maximum number of experts, associate experts, and ordinary personnel in the human resources policy, constraints (5) to (8) indicate the cost limit, and constraints (9) to (11) correspond to the proportion limit of experts, quasi experts and ordinary personnel in the human resources policy.

\section{SOLUTION AND ANALYSIS OF LINEAR PROGRAMMING MODEL OF}

Table 3 The calculation results of model

\begin{tabular}{|c|c|c|c|c|c|c|c|c|c|c|c|}
\hline Variable & $x_{1}$ & $x_{2}$ & $x_{3}$ & $x_{4}$ & $x_{5}$ & $x_{6}$ & $x_{7}$ & $x_{8}$ & $x_{9}$ & $x_{10}$ & $x_{11}$ \\
\hline Value & 1 & 1 & 1 & 2 & 1 & 1 & 2 & 3 & 5 & 4 & 2 \\
\hline Variable & $x_{12}$ & $x_{13}$ & $x_{14}$ & $x_{15}$ & $x_{16}$ & $x_{17}$ & $x_{18}$ & $x_{19}$ & $x_{20}$ & $x_{21}$ & cost \\
\hline Value & 1 & 6 & 3 & 8 & 2 & 1 & 1 & 1 & 1 & 3 & 20180000 \\
\hline
\end{tabular}

The minimum cost of human resource allocation for this model is 20180000 yuan, which basically meets the company's human resource cost tolerance, but the values of decision variables are all greater than or equal to 1 , which means that each position has at least one personnel and obviously accords with the characteristics of the departmental balance of human resources allocation in Chinese state-owned enterprises, which is a human resources allocation optimization plan that the company can accept.

\section{CONCLUSION}

The goal of this paper is to employ the best human resources with limited cost and realize the optimal distribution as far as possible. This distribution must consider the historical characteristics, corporate culture characteristics and policy characteristics of China's state-owned enterprises. Otherwise, the optimal scheme can only be the best scheme in mathematics rather than the best scheme that can be accepted and implemented by enterprises.

Based on the historical characteristics, corporate culture characteristics and policy characteristics of China's stateowned enterprises, this paper studies the integer planning of human resources under the control of cost objectives. An effective quantitative analysis approach to human resource planning considering the unique corporate culture of China's state-owned enterprises. A linear programming model for human resource analysis of state-owned enterprises in China is constructed, and the intention of human resource planning is expressed accurately. The application in a typical state-

\section{HUMAN RESOURCES IN TYPICAL AEROSPACE RESEARCH INSTITUTIONS}

The human resource planning model is established above, then we solve it with the help of Python software. The model includes 21 decision variables with integer value, so the integer programming module is called to complete the model. The results are as follows: owned enterprise in China shows that this method can take into account the historical characteristics and corporate culture of state-owned enterprises in China Characteristics and policy characteristics, the optimization results can be accepted as the optimization plan by the actual user.

\section{REFERENCES}

[1] Matteo Fischettia, Michele Monaci b. Using a general-purpose Mixed-Integer Linear Programming solver for the practical solution of real-time train rescheduling [J]. European Journal of Operational Research, 2017, 263 (1):258-264.

[2] Yun Yang a, b, c , Shijie Zhang a , b , * , Yunhan Xiao a , b. An MILP (mixed integer linear programming) model for optimal design of district-scale distributed energy resource systems [J]. Energy, 2015, 1901-1905.

[3] Eyyüb Y. Kıb,s . I. Esra Büyüktahtakın. Optimizing invasive species management: A mixed-integer linear programming approach [J]. European Journal of Operational Research, 2017, 259 ( ): 308-321.

[4] ZHANG LiLi *a,b,c . An Inverse Optimization Model for Human Resource Allocation Problem Considering Competency Disadvantage Structure [J]. Procedia Computer Science, 2017, 112 (2017) :16111622 
[5] Schouwenaars T, Moor B D, Feron E, et al. Mixed Integer Programming for Multi-Vehicle Path

Planning[C]// Control Conference. IEEE, 2015.

[6] Inagaki S, Egami T, Suzuki T, et al. Nonintrusive appliance load monitoring based on integer programming $[\mathrm{J}]$. Electrical Engineering in Japan, 2011, 174(2):18-25.

[7] Yankov D, Rajan S, Ratnaparkhi A. Integer Programming for Multi-class Active Learning[C]// ICDMW 2010, The 10th IEEE International Conference on Data Mining Workshops, Sydney, Australia, 14 December 2010. IEEE, 2010. 